\title{
ROMANIAN
}

NEUROSURGERY

Vol. XXXIV | No. 2 June 2020

\section{Endoscopic third ventriculostomy for obstructive hydrocephalus}

\author{
Hassan Z.A. Dixon, \\ Yasir M. Hamandi, \\ Ammar M.A. Mahmmoud, \\ Samer S. Hoz, \\ Zahraa F. Al-Sharshahi
}




\section{Endoscopic third ventriculostomy for obstructive hydrocephalus}

\author{
Hassan Z.A. Dixon ${ }^{1}$, Yasir M. Hamandi ${ }^{2}$, Ammar M.A. \\ Mahmmoud $^{3}$, Samer S. Hoz ${ }^{4}$, Zahraa F. Al-Sharshahi ${ }^{5}$ \\ ${ }^{1}$ Neurosurgeon F.I.C.M.S., Al-Mawanee General Hospital, Basra, IRAQ \\ 2 Professor of Neurosurgery, Al-Nahrain College of Medicine, \\ Baghdad, IRAQ \\ ${ }^{3}$ Neurosurgeon, Neurosurgery Teaching Hospital, Baghdad, IRAQ \\ 4 Neurosurgeon (FRCS), Department of Neurosurgery, Neurosurgery \\ Teaching Hospital, Baghdad, IRAQ \\ ${ }^{5} \mathrm{MB}, \mathrm{BCh} \mathrm{BAO}$ (NUI, RCSI), LRCP \& SI, Royal College of Surgeons in \\ Ireland (Alumnus), Dublin, IRELAND
}

\begin{abstract}
Introduction: Obstructive hydrocephalus has long been managed by valveregulated shunts. These shunts are associated with a myriad of short and long-term complications. This has fuelled interest in Endoscopic Third Ventriculostomy (ETV) which provides a more physiological pathway for cerebrospinal fluid (CSF) diversion while avoiding many shunt-related complications.
\end{abstract}

Aim: The objective of this study is to analyse the outcomes of ETV at our institution, focusing on the indications, success rates, and short-term complications.

Methods: Between July 2010 and September 2015, 47 patients with obstructive hydrocephalus underwent ETV at the Neurosurgery Teaching Hospital in Baghdad/ Iraq. We retrospectively analysed the data of these patients using hospital health records. Simple statistics were performed using SPSS Version 20. A standardized surgical technique was employed in all cases.

Results: The mean age was 4.4 years (range 40 days - 38 years). The male: female ratio was $1.23: 1$ ( $55 \%$ males and $45 \%$ females). The most common cause of obstructive hydrocephalus in patients undergoing ETV was aqueductal stenosis (62\%; $\mathrm{N}=29$ ). The second most common cause was posterior fossa tumours (23\%; $\mathrm{N}=11$ ). The overall success rate for ETV was $68 \%$. The net post-operative complication rate was $13 \%(\mathrm{~N}=6)$. CSF leak and seizures were the only two charted post-operative complications at the rates of $9 \%(\mathrm{~N}=4)$ and $4 \%(\mathrm{~N}=2)$, accordingly. No deaths were recorded.

Conclusion: ETV is a viable alternative to shunt insertion in a select group of patients with obstructive hydrocephalus, with acceptable success rate and safety profile.

\section{INTRODUCTION}

Hydrocephalus is a condition that results when excess cerebrospinal fluid (CSF) accumulates in the cerebral ventricles resulting in ventricular dilatation and raised intracranial pressure (Lu, Chen, Weng, \& Xu, 2019). Hydrocephalus is divided into communicating and non-communicating

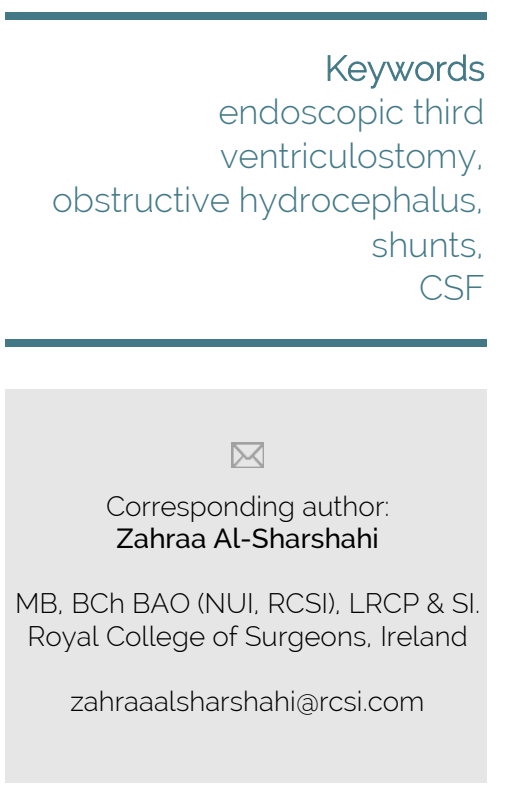

Copyright and usage. This is an Open Access article. distributed under the terms of the Creative Commons Attribution Non-Commercial No Derivatives License (https://creativecommons org/licenses/by-nc-nd/4.0/) which permits noncommercial re-use, distribution, and reproduction in any medium, provided the original work is unaltered and is properly cited.

The written permission of the Romanian Society of Neurosurgery must be obtained for commercial re-use or in order to create a derivative work.

ISSN online 2344-4959

(C) Romanian Society of Neurosurgery

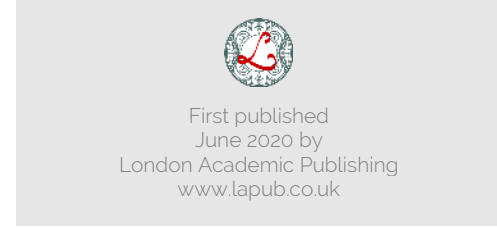


(Aka. obstructive) subtypes, as per Dandy's classification (Lu et al., 2019). Non-physiological CSF diversion using valve-regulated ventriculo-peritoneal and ventriculo-atrial shunts has dominated the field of hydrocephalus management over the past 45 years. However, shunts come with many complications including infections, displacement, and hardware failure. Failure rates are reported at $25-40 \%$ in the first year then $5-10 \%$ per year thereafter (Deopujari, Karmarkar, \& Shaikh, 2017). The significant morbidity imposed by these shunts and the need for frequent revisions has warranted the search for novel treatment options (Mugamba \& Stagno, 2013).

First introduced by mixter in 1923, Endoscopic Third Ventriculostomy (ETV) has regained popularity in the last two decades as an attractive treatment option for hydrocephalus (Mixter, 1923). In fact, ETV for the treatment of obstructive hydrocephalus is currently the most commonly performed endoscopic neurosurgical procedure (M. Gangemi et al., 1999) (Hellwig et al., 2005). Desirable qualities of ETV include 1) its physiological mechanism of CSF diversion, 2) its minimally invasive nature and 3) the absence of long-term hardware and all its associated complications (Mugamba \& Stagno, 2013).

Since it's advent in the early 1990s, ETV has shown the highest success rate amongst patients is obstructive hydrocephalus caused by acqueductal stenosis, both congenital and acquired (Mugamba \& Stagno, 2013). Nonetheless, both the surgical techniques and indications for ETV are constantly being refined. In the last few decades, many authors have been calling to expand the indications for ETV and numerous reports have been published to support this notion. (Beems \& Grotenhuis, 2004) (Brockmeyer, Abtin, Carey, \& Walker, 1998) (Choi, Kim, \& Kim, 1999) (Cinalli et al., 1999) (Feng et al., 2004) (Grunert, Charalampaki, Hopf, \& Filippi, 2003) (Scarrow, Levy, Pascucci, \& Albright, 2000) (Schroeder, Niendorf, \& Gaab, 2002) (Tisell, Almström, Stephensen, Tullberg, \& Wikkelsö, 2000).

In their systematic review and meta-analysis that compared the failure rates of obstructive hydrocephalus vs shunt insertion for patients with non-communicating hydrocephalus, Rasul et al concluded that ETV has statistically non-significant advantage over shunts; it does, however, appear to provide long-term survival benefit specifically in patients with congenital acqueductal stenosis (Rasul, Marcus, Toma, Thorne, \& Watkins, 2013).

In Iraq, ETV is still a relatively novel modality. In this paper, we aim to report our experience with ETV in the management of patients with obstructive hydrocephalus, which is one of the earliest reports in this field from our country.

\section{PATIENTS AND METHODS}

We conducted a retrospective analysis of a consecutive sample of 47 patients who underwent ETV for obstructive hydrocephalus at the Neurosurgery Teaching Hospital in Baghdad (NTH) for the period between July 2010 and September 2015. The aim of this study was to determine the success rate of ETV at our institution and to identify the main complications. A clinicoradiological criterion was implemented in our study. Patients were deemed candidates for ETV if they 1) presented with symptoms related to hydrocephalus such as raised ICP or enlarging head circumference and 2) had an MRI-confirmed diagnosis of obstructive hydrocephalus. Patients with communicating hydrocephalus were excluded from the study. The follow-up period ranged between six months and six years ( 6 months- 6 years). The success of ETV was defined by a combination of clinical and radiological criteria and ultimately by "shunt-independence". The clinical criteria revolved around the resolution of symptoms and signs caused by the high intracranial pressure by the 3-month follow-up visit. The radiological criteria were defined as the decrease in ventricular size or the arrest of ventriculomegaly as determined by Ultrasonography (US) and/or Computed Tomography (CT), using the Evans Index or the fronto-Occipital horn ratio. All data were obtained from the hospital health records at the NTH and statistics were performed using SPSS Version 20.

\section{OpERATIVE TECHNIQUE}

All operations were performed under general anesthesia. During each surgery, the fowling steps were followed:

- The patient was placed in a supine position with the head resting on a doughnut-shaped head rest.

- The head and neck were flexed at $\left(15^{\circ}\right)$.

- A Longitudinal skin incision was made just in front of coronal suture to the right of the mid-pupillary 
line $(3 \mathrm{~cm}$ off mid line $\& 1 \mathrm{~cm}$ anterior to coronal suture).

- The skin and periosteum were opened as a single layer with visual identification of coronal suture.

- A burr hole was drilled abutting the anterior border of coronal suture.

- The dura was coagulated and retracted in a cruciate fashion using a bipolar.

- The pia and arachnoid were coagulated and opened sharply in a cruciate fashion.

- The articulated arm of the endoscope was installed as close as possible to the patient's head.

- Warm ringer lactate solution was connected to the sheath at a height of $15 \mathrm{~cm}$ from the patient's ear.

- A Rigid sheath $(8 \mathrm{~mm})$ with its trocar inside was advanced slowly into the brain tissue aiming the tip of the sheath at the inner canthus in mediolateral plane and towards the tragus in antero-posterior plane.

- A sudden give up was used as an indication that the ventricle has been punctured. The trochar was then removed.

- A telescope with an attached light source and camera (3S) was introduced inside the sheath and locked in the zero position.

- The Foramen of Monro was identified, the arm was released and the sheath was introduced through foramen and placed just above the mammillary body.

- The thinned floor of the 3rd ventricle at the region of the tuber cinereum was identified and punctured using the fenestration forceps.

- The Ringer solutions was allowed to circulate in and out to verify the stoma opening.

- The endoscope was then withdrawn slowly while visualising the entry track.

- Cylindrical pieces of Gelfoam were placed in the track and on the burr hole followed by subcutaneous tissue and skin closure.

\section{RESULTS}

Our sample contained a heterogeneous group of patients in relation to the national geographic distribution, age range, and hydrocephalus etiology. The mean age was 4.4 years (range 40 days -38 years). The male: female ratio was 1.23:1 (55\% males and $45 \%$ females). The most common cause of obstructive hydrocephalus in patients undergoing ETV was acqueductal stenosis (62\%; $N=29$ ). The second most common cause was posterior fossa tumors (23\%; $\mathrm{N}=11)$. Other aetiologies included third ventricle arachnoid cyst $(11 \% ; \mathrm{N}=5)$, choroid plexus tumor of the lateral ventricle $(2 \% ; \mathrm{N}=1)$ and thalamic tumors $(2 \% ; N=1)$. The overall success rate for ETV was $68 \%$. Subgroup analysis showed that success rates were $62 \%$ and $78 \%$ for patients with acqueductal stenosis and posterior fossa tumors, respectively. Regarding the age group, the success rate for the younger population (below 10 years) was (62-65\%). In the subset of patients with unclear cerebrospinal fluid (CSF), the success rate was $22 \%$. No intraoperative complications were encountered. The net post-operative complication rate was 13\% $(\mathrm{N}=6)$ and spontaneous closure was charted in $32 \%$ $(\mathrm{N}=15)$. CSF leak and seizure were the only two recorded postoperative complications at the rates of $9 \%(\mathrm{~N}=4)$ and $4 \%(\mathrm{~N}=2)$, accordingly. The mortality rate was $0 \%(\mathrm{~N}=0)$. None of the patients needed redo ETV or shunt insertion as per their corresponding last follow-up visits.

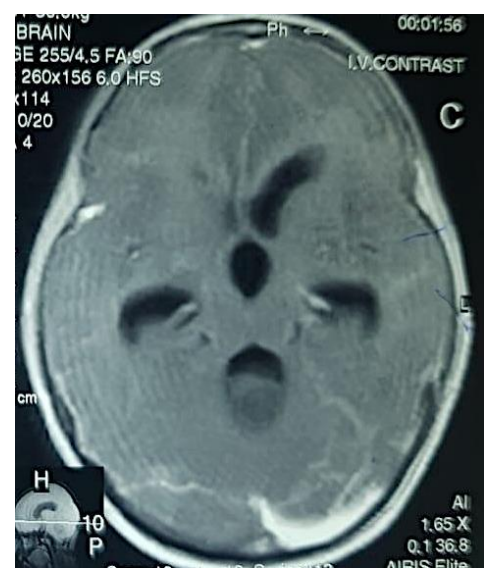

Figure 1.

A. nine-year-old female with obstructive hydrocephalus due to 4th ventricular tumor

(histopathologically proved WHO grade 4 Ependymoma). A: PreETV axial T1-weighted brain MRI with contrast showing hydrocephalus with ballooning of the 3rd ventricle and dilatation of both the frontal and temporal horns of lateral ventricles.

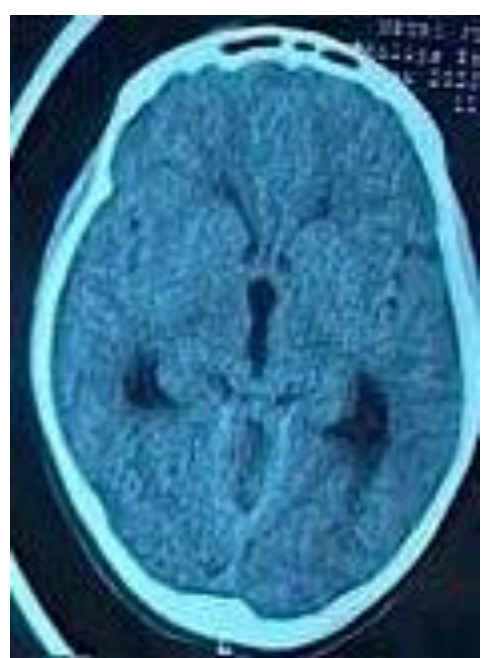

B: Early post-ETV brain CT scan (axial section) showing improvement of ventricular dilation with normal shape and size of the 3rd ventricle and the frontal horn of lateral ventricles. 


\section{DISCUSSION}

ETV is an important treatment option in the management of hydrocephalus. In our cohort of 47 patients with obstructive hydrocephalus, the two most common indications for ETV were acqueductal stenosis and posterior fossa tumors; this corresponds to the results published by Bouras et.al in their systematic review and meta-analysis ( $T$. Bouras \& S. Sgouros, 2012).

Recently, ETV has replaced extra-cranial shunts as the first-line treatment for occlusive hydrocephalus caused by acqueductal stenosis. Although the efficacy of ETV has been most established with the congenital forms of acqueductal stenosis, it is still a viable treatment option for other acquired aetiologies including those attributed to inflammatory and neoplastic processes (Hellwig et al., 2005). This finding was also reflected in our results, wherein patients with acqueductal stenosis had the highest success rates.

ETV has also proven effective in the management of occlusive hydrocephalus in patients with posterior fossa tumors (Amano et al., 2002) (Ruggiero et al., 2004) (Cinalli et al., 1999) (Schijman, Peter, Rekate, Sgouros, \& Wong, 2004) (Sainte-Rose et al., 2001). The incidence of pre-operative hydrocephalus in these patients is estimated at $80 \%$, with $25-30 \%$ progressing to persistent post-operative hydrocephalus necessitating surgical intervention (Hellwig et al., 2005). In their series of 206, SainteRose et al concluded that when performed prior to craniotomy, ETV reduced the incidence and progression of post-operative hydrocephalus (Sainte-Rose et al., 2001). However, there exists no consensus regarding the timing and the definitive treatment modality to be used in the management of these patients (Hellwig et al., 2005).

Since it's advent in the late 1980s and early 1990s, much experience has been gained with ETV as a management tool in patients with obstructive hydrocephalus. On the other hand, the efficacy of ETV in communicating hydrocephalus has not been scientifically established and is currently under investigation, with some authors reporting encouraging results (Hailong et al., 2008) (Meier, Zeilinger, \& Schönherr, 2000) (Michelangelo Gangemi, Maiuri, Buonamassa, Colella, \& de Divitiis, 2004). At our institution, patients with communicating hydrocephalus are not currently considered candidates for ETV.
To date, patient selection criteria for ETV is a debatable issue in the neurosurgical community; i.e. there is no clear definition of "ETV-eligible" patients and patient selection is currently based on local institutional policies, individual surgeon's experience and patient preference. (M. Gangemi et al., 1999) (Triantafyllos Bouras \& Spyros Sgouros, 2012).

Evaluation of ETV outcome has been mainly based on a clinicoradiological criteria. Clinical criteria focus on symptomatic improvement and shuntindependence while the radiological criteria centers on the reduction of the ventricular size and/or cessation of its growth (Buxton, Turner, Ramli, \& Vloeberghs, 2002) (Deopujari et al., 2017). However, some recent evidence tells us that the change in ventricular size is an unreliable indicator, especially in the early postoperative period. (Schwartz, Yoon, Cutruzzola, \& Goodman, 1996) (Feng et al., 2004). Success rates with ETV have been reported to be between 50-90\% (Hellwig et al., 2005). Beams and Grotenhius have reported the largest series thus far on patients with ETV (339 cases). In the aforementioned series, shunt independence was charted in 258 patients, with a complication rate of 7.7\%. (Beems \& Grotenhuis, 2004).

Regarding factors that predict poor outcomes after ETV, a history of shunt infection and postoperative meningitis have been identified as independent risk factors for ETV failure (Fukuhara, Vorster, \& Luciano, 2000). None of our patients harbored either risk factor.

Both the immediate and long-term complications associated with ETV are currently insufficiently reported in the literature to draw solid conclusions. There exist many inconsistencies in the reported intra-operative, immediate and delayed postoperative complications. In one systematic review, the mortality rate was reported as $0.22 \%$ and the permanent morbidity rate was $2.1 \%$. The most common charted complications were CSF infections (1.8\%) and CSF leak (1.7\%) (T. Bouras \& S. Sgouros, 2012). Further studies have also reported mortality rates below 1\% (Cohen, 1994; M. Gangemi et al., 1999; Jones, Kwok, Stening, \& Vonau, 1994; Teo \& Jones, 1996). In our study, no deaths were recorded as per the last follow-up visit for each patient.

The obvious shortcomings in our study are 1) the short follow-up period and 2) the small cohort size. In fact, these two limitations are shared by the majority of the related reports in the literature, an 
observation that highlights the need for multi-center, prospective, long-term studies to elucidate the longterm outcomes of ETV.

\section{CONCLUSION}

ETV is a promising treatment strategy for patients with obstructive hydrocephalus. However, many questions remain unanswered in relation to its longterm efficacy and safety, calling for further research in this area.

\section{REFERENCES}

1. Amano, T., Inamura, T., Nakamizo, A., Inoha, S., Wu, C.-M., \& Ikezaki, K. (2002). Case management of hydrocephalus associated with the progression of childhood brain stem gliomas. Child's nervous system : ChNS : official journal of the International Society for Pediatric Neurosurgery, 18(11), 599-604. doi:10.1007/s00381-002-0637-5.

2. Beems, T., \& Grotenhuis, J. A. (2004). Long-term complications and definition of failure of neuroendoscopic procedures. Child's nervous system : ChNS : official journal of the International Society for Pediatric Neurosurgery, 20(11-12), 868-877. doi:10.1007/s00381-004-0945-z.

3. Bouras, T., \& Sgouros, S. (2012). Complications of endoscopic third ventriculostomy: a systematic review. Acta neurochirurgica. Supplement, 113, 149-153. doi:10.1007/978-3-7091-0923-6_30.

4. Bouras, T., \& Sgouros, S. (2012). Complications of endoscopic third ventriculostomy: a systematic review. Acta Neurochir Suppl, 113, 149-153. doi:10.1007/978-37091-0923-6_30.

5. Brockmeyer, D., Abtin, K., Carey, L., \& Walker, M. L. (1998). Endoscopic third ventriculostomy: an outcome analysis. Pediatric neurosurgery, 28(5), 236-240. doi:10.1159 1000028657.

6. Buxton, N., Turner, B., Ramli, N., \& Vloeberghs, M. (2002). Changes in third ventricular size with neuroendoscopic third ventriculostomy: a blinded study. Journal of neurology, neurosurgery, and psychiatry, 72(3), 385-387. doi:10.1136/jnnp.72.3.385.

7. Choi, J. U., Kim, D. S., \& Kim, S. H. (1999). Endoscopic surgery for obstructive hydrocephalus. Yonsei medical journal, 40(6), 600-607. doi:10.3349/ymj.1999.40.6.600.

8. Cinalli, G., Sainte-Rose, C., Chumas, P., Zerah, M., Brunelle, F., Lot, G. Renier, D. (1999). Failure of third ventriculostomy in the treatment of aqueductal stenosis in children. Journal of neurosurgery, 90(3), 448-454. doi:10.3171/jns.1999.90.3.0448.

9. Cohen, A. R. (1994). Ventriculoscopic surgery. Clinical neurosurgery, 41, 546-562.

10. Deopujari, C. E., Karmarkar, V. S., \& Shaikh, S. T. (2017). Endoscopic Third Ventriculostomy: Success and Failure. Journal of Korean Neurosurgical Society, 60(3), 306-314. doi:10.3340/jkns.2017.0202.013.

11. Feng, H., Huang, G., Liao, X., Fu, K., Tan, H., Pu, H., ... Zhao, D. (2004). Endoscopic third ventriculostomy in the management of obstructive hydrocephalus: an outcome analysis. Journal of neurosurgery, 100(4), 626-633. doi:10.3171/jns.2004.100.4.0626.

12. Fukuhara, T., Vorster, S. J., \& Luciano, M. G. (2000). Risk factors for failure of endoscopic third ventriculostomy for obstructive hydrocephalus. Neurosurgery, 46(5), 11001111. doi:10.1097/00006123-200005000-00015.

13. Gangemi, M., Donati, P., Maiuri, F., Longatti, P., Godano, U., \& Mascari, C. (1999). Endoscopic third ventriculostomy for hydrocephalus. Minimally invasive neurosurgery: MIN, 42(3), 128-132. doi:10.1055/s-2008-1053384.

14. Gangemi, M., Maiuri, F., Buonamassa, S., Colella, G., \& de Divitiis, E. (2004). Endoscopic third ventriculostomy in idiopathic normal pressure hydrocephalus. Neurosurgery, 55(1), 129-134. doi:10.1227/01.neu.00001 26938.12817.dc.

15. Grunert, P., Charalampaki, P., Hopf, N., \& Filippi, R. (2003). The role of third ventriculostomy in the management of obstructive hydrocephalus. Minimally invasive neurosurgery: MIN, 46(1), 16-21. doi:10.1055/s-200337957.

16. Hailong, F., Guangfu, H., Haibin, T., Hong, P., Yong, C., Weidong, L., \& Dongdong, Z. (2008). Endoscopic third ventriculostomy in the management of communicating hydrocephalus: a preliminary study. J Neurosurg, 109(5), 923-930. doi:10.3171/JNS/2008/109/11/0923.

17. Hellwig, D., Grotenhuis, J. A., Tirakotai, W., Riegel, T., Schulte, D. M., Bauer, B. L., \& Bertalanffy, H. (2005). Endoscopic third ventriculostomy for obstructive hydrocephalus. Neurosurgical review, 28(1), 1-38. doi:10.1007/s10143-004-0365-2.

18. Jones, R. F., Kwok, B. C., Stening, W. A., \& Vonau, M. (1994). Neuroendoscopic third ventriculostomy. A practical alternative to extracranial shunts in non-communicating hydrocephalus. Acta neurochirurgica. Supplement, 61, 79-83. doi:10.1007/978-3-7091-6908-7_14.

19. Lu, L., Chen, H., Weng, S., \& Xu, Y. (2019). Endoscopic Third Ventriculostomy versus Ventriculoperitoneal Shunt in Patients with Obstructive Hydrocephalus: Meta-Analysis of Randomized Controlled Trials. World neurosurgery, 129, 334-340. doi:10.1016/j.wneu.2019.04.255.

20. Meier, U., Zeilinger, F. S., \& Schönherr, B. (2000). Endoscopic ventriculostomy versus shunt operation in normal pressure hydrocephalus: diagnostics and indication. Minimally invasive neurosurgery: MIN, 43(2), 87-90. doi:10.1055/s-2000-8325.

21. Mixter, W. J. (1923). Ventriculoscopy and Puncture of the Floor of the Third Ventricle. The Boston Medical and Surgical Journal, 188(9), 277-278. doi:10.1056/N EJM192303011880909.

22. Mugamba, J., \& Stagno, V. (2013). Indication for endoscopic third ventriculostomy. World neurosurgery, 79(2 Suppl), S20.e19-S20.e23. doi:10.1016/j.wneu. 2012.02.016. 
23. Rasul, F. T., Marcus, H. J., Toma, A. K., Thorne, L., \& Watkins, L. D. (2013). Is endoscopic third ventriculostomy superior to shunts in patients with non-communicating hydrocephalus? A systematic review and meta-analysis of the evidence. Acta neurochirurgica, 155(5), 883-889. doi:10.1007/s00701-013-1657-5.

24. Ruggiero, C., Cinalli, G., Spennato, P., Aliberti, F., Cianciulli, E., Trischitta, V., \& Maggi, G. (2004). Endoscopic third ventriculostomy in the treatment of hydrocephalus in posterior fossa tumors in children. Child's nervous system : ChNS : official journal of the International Society for Pediatric Neurosurgery, 20(11-12), 828-833. doi:10.1007/s00381-004-0938-y.

25. Sainte-Rose, C., Cinalli, G., Roux, F. E., Maixner, R., Chumas, P. D., Mansour, M., . . Renier, D. (2001). Management of hydrocephalus in pediatric patients with posterior fossa tumors: the role of endoscopic third ventriculostomy. Journal of neurosurgery, 95(5), 791-797. doi:10.3171/jns.2001.95.5.0791.

26. Scarrow, A. M., Levy, E. I., Pascucci, L., \& Albright, A. L. (2000). Outcome analysis of endoscopic III ventriculostomy. Child's nervous system : ChNS : official journal of the International Society for Pediatric Neurosurgery, 16(7), 442-445. doi:10.1007/s003810 000307.
27. Schijman, E., Peter, J. C., Rekate, H. L., Sgouros, S., \& Wong, T. T. (2004). Management of hydrocephalus in posterior fossa tumors: how, what, when? Child's nervous system : ChNS : official journal of the International Society for Pediatric Neurosurgery, 20(3), 192-194. doi:10.1007 /s00381-003-0900-4.

28. Schroeder, H. W. S., Niendorf, W.-R., \& Gaab, M. R. (2002). Complications of endoscopic third ventriculostomy. Journal of neurosurgery, 96(6), 1032-1040. doi:10.3171/jns.2002.96.6.1032.

29. Schwartz, T. H., Yoon, S. S., Cutruzzola, F. W., \& Goodman, R. R. (1996). Third ventriculostomy: post-operative ventricular size and outcome. Minimally invasive neurosurgery: MIN, 39(4), 122-129. doi:10.1055/s-20081052231.

30. Teo, C., \&Jones, R. (1996). Management of hydrocephalus by endoscopic third ventriculostomy in patients with myelomeningocele. Pediatric neurosurgery, 25(2), 57-63. doi:10.1159/000121098.

31. Tisell, M., Almström, O., Stephensen, H., Tullberg, M., \& Wikkelsö, C. (2000). How effective is endoscopic third ventriculostomy in treating adult hydrocephalus caused by primary aqueductal stenosis? Neurosurgery, 46(1), 104-111. 